\title{
Particularity of suicide in the countries of the European Union
}

\author{
Andrei Scripcaru, Costel Marius Frăsilă, Silvia Şpac, \\ Mădălina Maria Diac, Călin Scripcaru
}

\begin{abstract}
Andrei Scripcaru - MD, PhD student, Grigore T.Popa University of Medicine and Pharmacy Iasi Costel Marius Frăsilă -"Ştefan cel Mare" University Suceava

Silvia Şpac - MD, Institute of Legal Medicine Iași

Mădălina Maria Diac - MD, PhD student, Grigore T.Popa University of Medicine and Pharmacy Iasi

Călin Scripcaru - MD, PhD, professor, "Ştefan cel Mare" University Suceava
\end{abstract}

\begin{abstract}
Starting from the bio-psycho-social concept developed by Petre Brânzei it is obvious that suicide has a complex motivation that combines genetic, psychological and social elements. The paper aims to analyze the social motivation in various countries of the European Union as the underlying mechanism triggering the suicidal gesture and especially the "trigger" factor that determines the transition to the act, are still unclear. It is most likely that important endocrine factors, possibly explaining the decrease in suicide rates in Europe from north to south, are involved. The decrease from east to west seems to be the consequence of higher living standards in the west, but also of more effective prophylactic measures in these countries.
\end{abstract}

\section{KEYWORDS:}

Suicide attempt, prophylaxis, triggers.

\section{SUICIDAL BEHAVIOUR AS A RESULT OF SOCIAL TRENDS AND PRESSURES} In its essence and by the multiple consequences it entails, suicide is an extremely important social problem, which is of a justified interest to sociologists, psychologists, criminologists, lawyers, doctors, to different categories of specialists, practitioners, representatives of the authority and, last but not least, to the public. A social problem - sociologists point out - is an undesirable and harmful condition for society, which affects its order requirements, prevents social change and has a negative impact on the existence, security and well-being of society members (1). 
rog

The statistics or estimates compiled by the World Health Organization are relevant in this respect, highlighting that suicide is a global problem of humanity, which manifests itself in all countries of the world with great intensity, being amplified by the conditions of the current crisis.(1)

Consistent with this interpretation of suicide as a social problem, sociologists believe that suicide rates can only be explained by social factors, independent of the biological traits, characteristics and mental tendencies of the individual $^{1}$. If the act of suicide as such may involve such individual characteristics and motivations, suicide rates are necessarily subjected to social trends and pressures, being - as the well-known sociologist É Durkheim pointed out. - a consequence of the "social acts" that manifest themselves and act in a particular society. And such social acts are, in fact, a product of social relations and types of human association, consisting of "ways of working, of thinking and feeling, external to the individual and which are endowed with a power of compulsion by virtue of which they are imposed on him" (Durkheim, 2).

\section{SUICIDE, CRISIS AND ECONOMIC PROSPERITY}

Émile Durkheim is probably the first sociologist to point out that "every people has a collective tendency towards suicide that is their own", as demonstrated (1999, pp. 247261) by the fact that as long as society does not change, the number of suicides remains constant" (Durkheim,2).

The increase in the extent of suicides Durkheim observes - occurs when society is changing, i.e. either in a state of economic crisis (in a negative sense) or in a state of economic prosperity (in a positive sense). "Any shaking of balance, even if it provokes abundance and increased social vitality, fosters suicide" (Durkheim,2).

Durkheim's theory seems, in one way or another, tested by the current economic crisis, although the data of various research carried out in this field are contradictory to each other. Thus, some studies have shown that periods of economic crisis lead to a significant increase in suicides, other studies have stressed that in such periods suicide is committed especially by vulnerable people (who are already affected by stress, mental disorders, unemployment, alcohol consumption, etc.), while other studies have pointed out, on the contrary, that in periods of economic recession the number of suicides decreases, due to the fact that individuals mobilize more strongly than in "normal" times to cope with life difficulties (Carey, 2011). Research undertaken in the United States has, on the other hand, highlighted the fact that, contrary to Durkheim's conception, suicide rates decrease during periods of economic expansion, with some exceptions, related to age groups. Thus, during the economic boom of the 1960 s, the suicide rates of the population in the 30 to 50 years interval increased in the United States, and during the recession in the middle of the 7th decade, suicide rates decreased among the elderly population, who were the beneficiary, among other things, of the Social Security program of the previous decade (Carey, 2011).

\section{SUICIDE IN EUROPE}

R.B. Ginsberg (1966) pointed out that suicide is "procyclical" in that suicide rates decrease during periods of economic depression and increase during periods of economic expansion. On the contrary, A.F. Short and J.F. Short (1954) have highlighted that suicide is "anti-cyclical": thus, during periods of economic prosperity, the suicide rate decreases and during periods of economic crisis it increases 
ry

A study by Bijou Yang (1992) on the evolution of the suicide rate in the United States between 1940 and 1984 disproved the assumptions circumscribed to Durkheim's conception. In this regard, the study found that: suicide rates did not increase during periods of economic boom or economic crisis in the United States, any change in these rates being dependent on the characteristics of the social groups involved. On the other hand, unemployment rates had a significant negative effect only on the suicide rate characteristic to white men, and the rate of participation of women in the workforce had a beneficial influence on suicide rates, both those characteristics to white women and those specific to black women.

\section{THE RELATION BETWEEN SUICIDE AND ECONOMIC CRISES}

A suggestive example that points out that suicide is determined by or is related to socioeconomic factors is the finding - resulting from social history studies - that, during periods of economic recession, the number of suicides of the population included in the age range of 25 to 64 years, increases.

The period of the Great Depression, for example, which began a decade earlier than the Second World War, is a suggestive example from this point of view. Thus, the sharp decline in economic indicators, in particular the decline in production, trade, unemployment and, by implication, income, has led to numerous suicides.

In the United States, for example, the average death rate by suicide per 100,000 inhabitants increased, compared to the previous period (1920-1928), by almost 50\% in 1929 and by $27 \%$ between 1930-1940. In the same country, during the most pronounced period of crisis, 1928-1933, when the unemployment rate reached $24 \%$, the highest suicide rates in
American history were reached. On the contrary, in 2000, when the US unemployment rate did not exceed $4 \%$, it was the lowest suicide rate in the country's history (Sternheimer, 2011).

Beyond such findings, it can be pointed out that suicidal rates recorded during the crisis that began in 2008 are much more pronounced, at least in Europe, than during the Great Depression (Stuckler, 2011).

As an example, the countries that faced the most difficulties during the economic crisis that began in 2008, such as Greece and Ireland, recorded the largest increase in the suicide rate (according to Mediafax, 2011).

In Greece, the number of suicides increased by $17 \%$ between 2007 and 2009, and some unofficial data even mention a $25 \%$ increase in 2010 (Kentikeles, Stucker et al., 2011). According to the Ministry of Health in Athens, in the first half of 2011, the number of suicides increased by $40 \%$ compared to the same period the year before (Stancu, 2011). Before the financial crisis, Greece had one of the lowest suicide rates in Europe: 2.8 per of one thousand inhabitants. In 2011, this figure doubled. Suicide attempts have also increased (Smith, 2011).

These trends, coupled with those aimed at doubling the number of murders and thefts between 2007 and 2010, complementary to the deterioration of the public health system due to lack of funds, have led US researchers at the University of Cambridge, Alex Kentikeleris and David Stuckler, to appreciate that a genuine "Greek tragedy" can be talked about (Kentikeles, Stucker et al., 2011).

In Ireland, during the same time period (20072009), when Ireland felt the strongest effects of the economic and financial crisis, the 


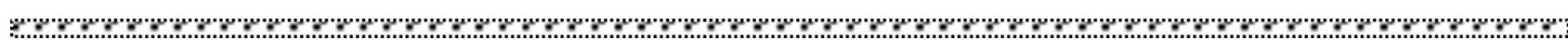

suicide rate increased by $15 \%$. In line with the data of the Report prepared by the Central Statistical Office of Ireland, from the end of 2006 to 2009, the suicide rate increased by $25 \%$, the highest annual rate ever recorded in this country (Queen, 2010).

The largest increases in the suicide rate occurred among the young population (15-24 years): $23 \%$ for men and $13 \%$ for women. The suicide of young people was, during that period, the 5th place in Europe, after the ones recorded in Estonia, Latvia, Lithuania and Finland (Queen, 2010). As a characteristic trend in Ireland, suicide acts were committed, in the years of crisis, mainly by the heads of young families, who faced numerous financial problems, which led them to consume alcohol excessively. On the other hand, there has been an increase in suicides in rural areas and in the construction industry, which have been most affected by the economic and financial crisis. Along with the effects of this crisis, alcohol and drug abuse were the factors that strongly enhanced suicidal behavior (Thomas, 2012).

With the exception of these two countries, almost all European countries have seen increases in suicide rates caused by the economic crisis.

A study carried out, for example, by David Stuckler and his collaborators on the evolution of the mortality rate recorded in 26 European countries during the economic crises of the last three decades, revealed that unemployment is one of the main factors associated with the increase in suicides among the population under the age of $65^{2}$. Thus an increase of more than $3 \%$ in the unemployment rate has strong effects on the suicide committed by this category of population. Based on the analyses carried out, these authors predicted that the period of economic crisis started in 2008 would have similar consequences (Stuckler et al., 2009).

The authors of the study processed data on mortality causes by age groups from the data compiled by the World Health Organization, and the information on unemployment trends characteristic to the adult population had taken them from statistics published by EUROSTAT.3 (Euro-indicators Calendar). As complete information on 17 of the 27 European countries was missing, the analysis focused mainly on 10 countries, six of which joined the European Union before 2004 (Austria, Finland, Greece, Ireland, the Netherlands and the United Kingdom), and four others joined the Union after 2004 (Czech Republic, Hungary, Lithuania and Romania). Data on the situation in the two groups of countries were evaluated in ration with the population size (Stuckler et al., 2011).

The findings of the study showed the following:

in both groups of countries, officially recorded unemployment rates did not increase until 2009, the year following the economic crisis. Since this year, the unemployment rate has risen rapidly in all 10 countries, by around $35 \%$ from the level reached in 2007 , with an increase between $2 \%$ and $6 \%$ across the European Union.

however, the steady decline in suicide rates, which was observed in both groups of countries before the start of the crisis, was simultaneously reversed in all the countries analysed. Thus, in 2008, the increase in suicide rates was less than $1 \%$ in countries that more recently joined the European Union and by around $7 \%$ in those countries that joined the Union a longer time before.

in 2009, the growth trend increased in all countries (at at least 5\% compared to 
2007), with the exception of Austria, which in 2009 recorded fewer suicides (with about 5\%) than in 2007.

surprisingly, Finland, which has one of the strongest social protection systems, has seen an increase of more than $5 \%$ in suicides compared to Austria, which also has a highly functioning social protection system;

Greece and Ireland, as we have already mentioned, have had the greatest increases in suicides. Latvia also had an increase of more than $17 \%$ between 2007 and 2008;

in the UK, the suicide rate increased from 6.14 per 100000 people in 2007, to 6.75 per 100000 in 2008, thus increasing by $10 \%$, remaining at the same level in 2009;

despite these fluctuations, that study could not identify a definite trend of deviation during the crisis period, compared to the past, in respect of all cases of mortality, except for suicides, which increased in magnitude and intensity, and car accidents, which decreased significantly, probably due to the decrease in the availability of machinery usage and of the use of more worn-out vehicles, which did not allow excessive speed in traffic.

Except for the difficulties faced by the authors of that study, due in particular to the difficulties in weighting the data, as well as the pronounced variations from one country to another, in terms of their availability (Romania is mentioned, in this respect), this study suggestively highlighted the association link (not necessarily causal) between periods of economic crisis and the increase in suicide rates.

\section{SUICIDE, WELL-BEING AND HEALTH CONDITIONS OF THE POPULATION}

Clearly, suicide is not an effect of factors or processes that act in isolation or autonomously. It should be noted, in this respect, that periods of crisis do not in themselves lead to an increase in suicide rates, but only through intermediate variables, such as: unemployment, declining of incomes, deterioration of quality of life, consumption of alcohol or drugs, disruption of physical health, but especially of mental health, etc. A period of crisis is complementary, in fact, to these changes in the lives of individuals, which affects - as the results of several studies and research highlights - the social well-being of the population. Suicide, as such, is a significant indicator of the decrease in social well-being and, first and foremost - as many experts in the field point out - of mental health.

As defined by the World Health Organisation, health, in its entirety, is an essential dimension of human life, which is an important indicator of social well-being and quality of life. It is a "condition of physical, mental and social well-being" that actually reflects the living standards of a particular community. ${ }^{3}$

However, as a whole, the findings of empirical research focusing on the link between periods of economic crisis and the deterioration of social well-being, including health status, are contradictory to each other. Thus, some analysts consider that, excluding suicides - which are an "exception" economic crises have no negative effects on health (Anderson, 2011, p. 2). Paradoxically, during the Great Depression, which preceded the Second World War, the overall mortality rate decreased for all age groups, but suicide rates increased.

With the exception of the influence of economic crises, there is an association link between the health of a population and its tendencies towards suicide, with variations from one country to another. Health status can 
best be highlighted through mortality rates.

But because mortality is different within different age groups and from one country to another, statistical institutes or offices have to sum them up and standardize them in different comparable ways.

In the period 2008-2009, for example, during which the economic crisis began and expanded, the lowest mortality rates for all cases of death in European countries were recorded in Switzerland, Italy, Iceland and Spain (between 490 and 520 deaths per hundred thousand inhabitants), and the highest rates were recorded in Lithuania and Latvia (over 1,000 deaths per hundred thousand inhabitants). Bulgaria, Romania and Hungary also had mortality rates of more than 900 deaths per hundred thousand inhabitants (OECD, 2010, p. 30-31) - see fig. 1

Fig. 1 Death rate for all deaths in 2008 for ten European countries

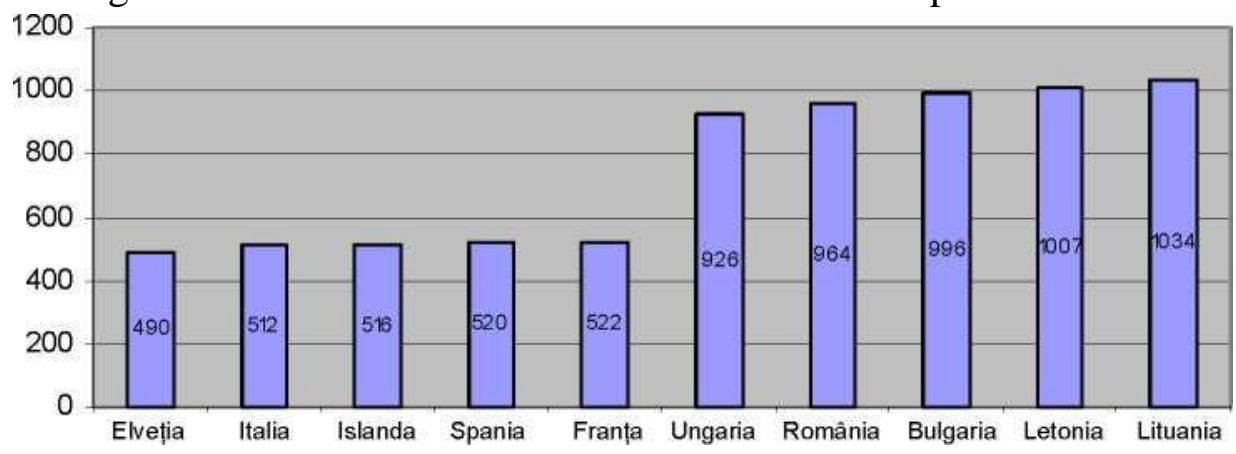

Source: OECD Health Data 2010

In terms of suicide rates, they were lower in Italy, Spain and Iceland (between 6.3 and about 12 per hundred thousand inhabitants) and higher in Lithuania (over 34 per hundred thousand inhabitants), Hungary and Latvia (approximately between 32-25 per hundred thousand inhabitants).

Bulgaria and Romania, respectively, recorded about 12 suicides per thousand inhabitants (fig 2).

Fig 2 Suicide mortality rate in 2008 (2009) in ten European countries

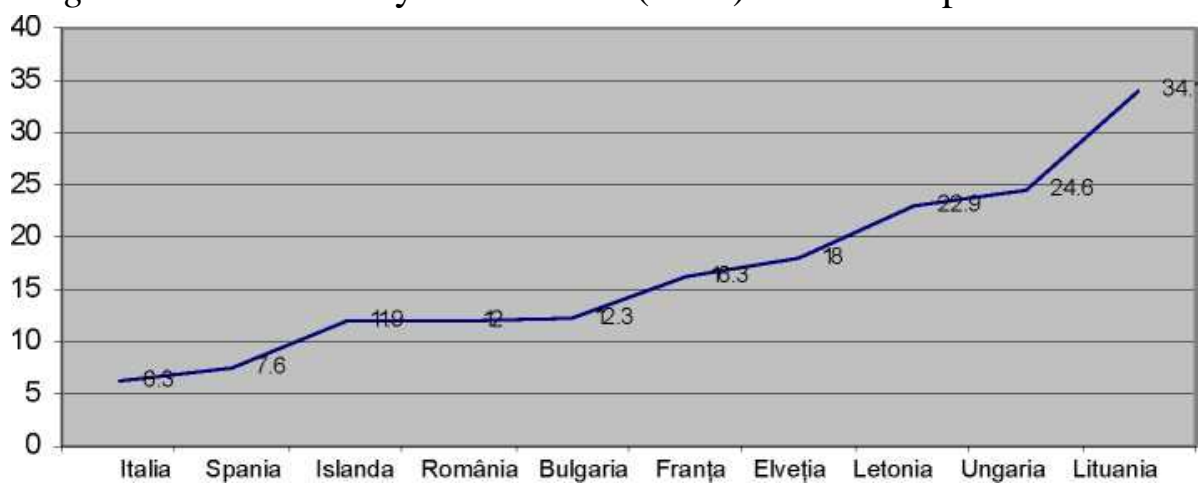

Source: Eurostat Statistics Data, 2010

Based on the data mentioned, a positive correlation between mortality rates - as indicators of population health - and suicide rates can be inferred. Thus, Italy, Spain and
Iceland, which had the lowest mortality rates among European countries, also had the lowest suicide rates. The exception is Switzerland, which had the lowest mortality 
rate in Europe, but recorded a medium-level suicide rate (18 per cent of thousands of inhabitants). By contrast, Lithuania and Latvia, which had the highest mortality rates of all European countries, also had the highest suicide rates. An exception is the case of Hungary, which had an average mortality rate, but instead recorded one of the highest suicide rates. A particular situation was recorded in Romania and Bulgaria, which, although had high mortality rates (immediately after those recorded by Lithuania and Latvia), had relatively low suicide rates, but about twice as high as those recorded, for example, by Switzerland.

These exceptions are explained, amongst others, by the variations between different countries in terms of unemployment, alcohol and drug use, the state of depression that characterizes individuals and, therefore, their mental health.

It should be noted, on the other hand, that both mortality rates and suicide rates are much higher among men than among women. Thus, the mortality rates of men exceeded with 50 to $100 \%$ that of women, while the suicide rates of the same men exceed those of women even 3-4 times (OECD, 2010). In the case of suicide attempts, the differences between the two sexes are smaller, among others, because women tend to use less lethal suicide methods than those used by men.

\section{SUICIDE, UNEMPLOYMENT AND MENTAL HEALTH}

In most countries with market economies there is a 'business cycle', characterized by an increase in unemployment during periods of economic recession and a reduction in it during periods of economic expansion (Kposowa, 2003). Such a cycle therefore has a special impact on suicides, especially those committed by the working population.
One of the main objectives of studies focused on the role of this cycle, in general, of socioeconomic factors in increasing or, on the contrary, lowering suicide rates is the relationship between suicide and unemployment. Socio-economic variables seem to have the greatest contribution to the impact of occupational status on suicide (Preti, 2003). Several studies have pointed out that a low level of occupational status of individuals correlates with a higher risk of suicide. In many European countries, changes in occupational rates have influenced suicide rates. Suicide risk is linked, among other things, to the fear of employees losing their jobs and the stress that characterizes the unemployed with regard to the drastic reduction of income and the deterioration of their living standards (Yur'iev et al., 2010).

Research carried out in the Member States of the European Union has shown, for example, that trends in the increase in national unemployment rates have been and are still associated with increased suicide rates and, among other factors, the increased incidence of mental illness or mental disorders ${ }^{4}$.

Except for these findings, several studies and research (Kposowa, 2001) have concluded that the effect of unemployment on suicide is more pronounced immediately after individuals become unemployed. As time goes on, the new unemployed adapt to their new status, which is why they are less inclined to commit suicide. In addition, with the passage of time, the unemployed can find work and leave the status of unemployed. These issues were ignored by studies dealing with the association link between unemployment and suicide and which did not take into account the duration of the period of unemployment. 
p.

Summarizing the main characteristics and effects of the relationship between suicide, unemployment and health, the Strategic Center for Suicide Prevention in the United States highlighted the following findings (Suicide Prevention Resource Center, 2008):

\section{UNEMPLOYMENT AFFECTS}

GENERAL HEALTH.

- Unemployment is associated with poor health and mortality through all cases of death (except cancer and strokes).

\section{UNEMPLOYMENT CONTRIBUTES TO THE RISK OF SUICIDE BUT DOES NOT "CAUSE" SUICIDE BY ITSELF.}

- Occupational status is just one of the factors that interacts with individuals, communities and societies, affecting suicide risk.

- Although unemployment is associated with increased suicide rates, many individuals may have lower employment rates due to poor mental health and drug use, which are also associated with increased suicide rates.

Unemployment causes financial difficulties and can lead to depression or other problems that individuals perceive as a loss of personal control.

Economic conditions, as such, are not sufficient to cause a suicidal act; in fact, we do not know any singular factor, i.e. sufficient by itself, to "determine" a suicidal act. Stressors such as losing a job, housing or retirement can produce feelings of shame, humiliation and despair, and in this context can precipitate the suicide attempts of those people who are already vulnerable or do not have enough resources to get support. In most, but not in all cases, mental health problems are among the factors that increase this vulnerability.
We can expect an acute economic crisis to lead to a suicide risk among working adults and in older adults whose retirement security is threatened.

\section{SUICIDE IN ROMANIA, ABOVE THE EUROPEAN AVERAGE IN THE MOST LIKELY AGE GROUPS}

Eurostat results were presented on Tuesday at the launch of the study "Depressive Disorder" New research directions", by doctors Camelia Popa, clinical psychologist, researcher in the Department of Psychology of the Romanian Academy, and Adela Ciobanu, psychiatrist at the "Alexandru Obregia" Hospital and teacher at the University of Medicine Bucharest.

According to Eurostat, the age groups with the highest incidence of suicide are: 15 - 19 years, 50 - 54 years and over 85 years.

Lithuania, the European country with the most suicides, has a suicide rate ten times higher than Greece, the country with the fewest suicides.

Suicide rates are low in southern European countries - Greece, Cyprus, Italy, Malta, Spain and Portugal - but also in the UK, and high in the Baltic and Central and Eastern European States - Lithuania, Hungary and Latvia, as well as Finland.

Suicide death rates are three times higher for men than for women across the European Union, with wide variations between countries.

In Romania, suicide among young people aged 15 to 19 has a rate of 6.3 deaths per 100,000 inhabitants, compared to the European average of 4.6. The male suicide rate is 9.2, compared to 6.9, the EU average and the female suicide rate is at 3.2, compared to 2.2, the EU average. 
For the age group 50 to 54 years, Romania has a rate of 22 suicides per 100,000 inhabitants for both sexes, compared to 18.3 , the European average. If the suicide rate among Romanian women aged 50 to 54 was below the European average (5 deaths per hundred thousand inhabitants, compared to 8.1 deaths per thousand inhabitants - the EU average), the male suicide rate was extremely high - 40.6, compared to 28.7 per 100000 inhabitants - the EU average.

At the top of the EU as frequency of suicide among young people are the Baltic and northern European countries - Lithuania, Estonia, Finland and Ireland. European countries with the fewest young suicides include Greece, Spain, the UK, Germany and France.

A significant and steady decrease in suicide rates among young people can be observed in the case of Hungary, which in 2010 had a suicide rate for the group 15 to 19 years lower than that of Romania, after Romania for decades was at the top of the European ranking as a frequency of suicide.

On the other hand, in the group of suicidal risk 50 - 54 years in the first places are Lithuanians, Hungarians, Slovenians and Polish. The countries with the fewest cases of suicide in this age group are Spain, the United Kingdom and Greece.

\section{ACKNOWLEDGMENTS AND DISCLOSURE}

The authors state that they are no declared conflicts of interest regarding this paper.

\section{REFERENCES}

1. Rădulescu S, Suicide in Europe in the Context of the Global Economic Crisis. The Romanian Journal of Sociology. 2012; 23(5-6):385-403.

2. Durkheim E. Suicide, Sociological Study, European Institute Publishing House. 1993.

3. A.F. Short, G.F. Short. SUICIDE AND HOMICIDE-SOME ECONOMIC, SOCIOLOGICAL AND PSYCHOLOGICAL ASPECTS OF AGGRESSION.1954

4. Kentikelenis A., Stucker D. et al. Health effects of financial crisis: omens of a Greek tragedy. The Lancet.2011;378(9801):1457-1458

5. E. Rădulescu. Sociologia sanatatii si a bolii. 2002

6. Health at a Glance: Europe 2000, OECD Publishing.2010.

7. World Health Organization. Impact of economic crises on mental health. Geneva. 2011

8. http://www.mediafax.ro/externe/criza-economicadetermina-mai-multe-sinucideri-dar-maiputine-accidente-auto-in-europa-8463984

9. De Gioannis A., De Leo D. Managing suicidal patientes in clinical practice. Open Journal of Psychiatry. 2012; 2:49-60.

10. Diekstra R.F.W., Gulbinat W., Kienhorst I., De-Leo D. Preventive Strategies on Suicide. Vol. 2. Co-publication WHO, Geneva E.J. Brill,1995

\section{Correspondence:}

Călin Scripcaru,

$\mathrm{MD}, \mathrm{PhD}$, professor, "Ştefan cel Mare" University Suceava, calinscripcaru 